\title{
AN OPENCV BASED EFFICIENT FACE RECOGNIZATION APPROACH FOR AUTOMATED ATTENDANCE UPDATION
}

\author{
Brahmananda Reddy D \\ MCA Scholar,School of CS \& IT, Dept. of MCA,Jain(Deemed-to-be) University, Bangalore \\ P R Kuber Gupta \\ MCA Scholar,School of CS \& IT, Dept. of MCA,Jain(Deemed-to-be) University, \\ Bangalore
}

Article DOI: https://doi.org/10.36713/epra4323

\begin{abstract}
Traditional way of taking attendance can lead to various anomalies such as proxy, misallocation of attendance register. The proposed method overcomes the defects that exists in the traditional method. The latest digital register tracks the student's presence by identifying and recognizing their details by using Machine learning algorithms.

KEYWORDS- digital register, identification, recognizing, attendance, machine learning
\end{abstract}

\section{INTRODUCTION}

A robotized framework for human face acknowledgment in a constant foundation for a school to stamp the participation of their Students. The coordinated face is utilized to check participation of the Student. Our framework keeps up the participation records of Students consequently.

In past there was Manual checking of participation of students, by this Data might be odds of loosing of every single understudy or there would be some fraudulent activities like proxy attendance by the students to the tutor.

We can enhance the security of this model by implementing IRIS retina scan for more secure and robust environment.

\section{LITERATURE REVIEW}

[1] In this paper author proposed a model that overcomes the disadvantages exists in the manual attendance system. By using face recognition and RFID it becomes easier in tracking student's presence.

[2] Author in this paper suggests that smart attendance system that is student tracking using face recognition and RFID helps in rapidly reducing capital on attendance system. Managing attendance through smart attendance system is much easier than traditional way.
The author of the paper performed thesis on the people living in Arab countries. Where girls wear veil and boys are beard this can create ambiguity in recognizing students face. This can be overcome by using certain pattern tracking in different genders which helps in segregating both male and female.

[3] The wordsmith in this paper has proposed a method to record attendance by surveilling classroom through video. This enhances the learning efficiency of students eluding traditional roll call procedure. It detects and marks student as absent when he/she uses mobile phone beyond threshold time.

[4] The transcriber of the paper proposed that participation mechanization utilizing face acknowledgment is a non-meddling strategy and it causes the administration to keep up an exact participation database as the test picture is passed through various levels. The in-time and out-time of the understudies is checked and dependent on the time the participation is checked. Consequently, this framework whenever actualized, it just so happens to be a verified and validated framework with elite.

[5] This system has been designed to automate the attendance maintenance. The main objective behind 


\section{EPRA International Journal of Research and Development (IJRD) \\ Volume: 5 | Issue: 4 | April 2020 \\ - Peer Reviewed Journal}

developing this system is to eradicate all the drawbacks and unconventional methods of manual attendance handling. The traditional methods lag the effectiveness of the system leading the time and paper wastage, and causes proxy attendance which is eliminated in automated system. So to overcome all such drawbacks of manual attendance, this framework would come out to be better and reliable solution with respect to both time and security. In this way, automated attendance system helps to distinguish between the faces in classroom and recognize the faces accurately to mark their attendance. The efficiency of the system can be improvised by fine

tasking of the training process.

\section{PROBLEM STATEMENT}

Recording student attendance using manual method has plenty number of flaws and this lead to development of RFID based attendance this method is also incorporated with some defects. This face recognition based attendance system reduces proxy of attendance, hence only those students will get attendance who are present physically, nobody else can give attendance on behalf of someone else.

Face recognition for attendance maintenance is one of the best way to tackle issues that are existing in the preceding methodologies.

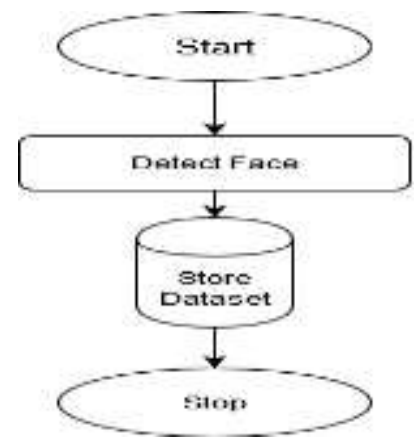

Fig 4.1 face detection and storage

- Face detection and storage: The model detects the face pattern and stores the image in the database for further usage.

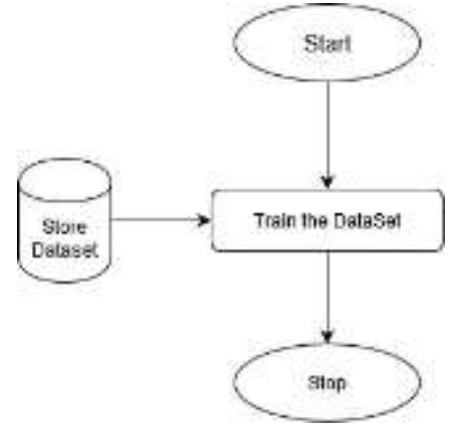

Fig 4.2 Image training

- Image training: Images that are stored in database get trained by storing different parameters of the image.

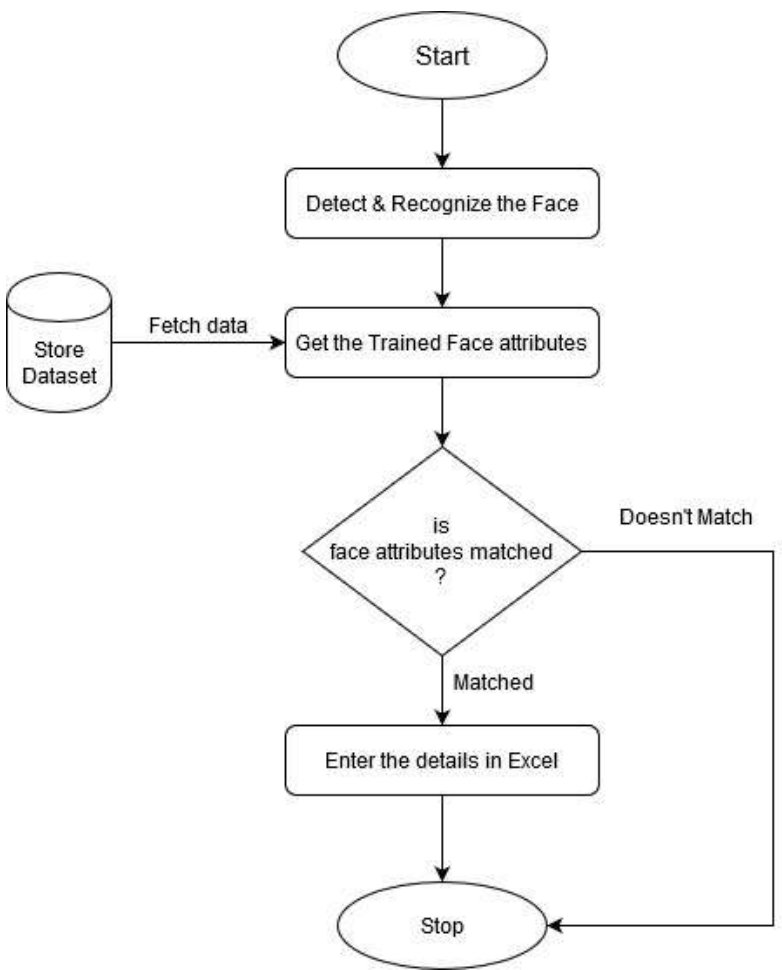

Fig 4.3 face recognition from database

- While detecting face for recognizing it with database, image of the person gets detected and checks whether there are any predefined patterns available for that image and if there is no available patterns person's face don't get recognized. 


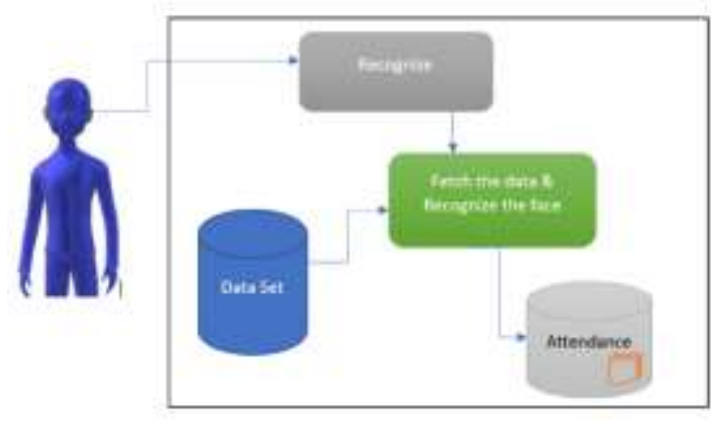

Fig 4.4 System Module

Initially student's face gets recognized and captured by the camera the user's attributes gets stored in the database based on the parameters that are predefined in the back end. Later while recording attendance, student's face gets scanned by the camera and the system logic matches for the patterns of that particular face in the database and if match is found then attendance of that specific student is marked. If student face is not matched with the patterns in the database, then unknown tag is displayed.

\section{RELATED TECHNOLOGIES}

Face detection technology

Face identification is a PC innovation being utilized in an assortment of uses that distinguishes human faces in computerized pictures. Face discovery additionally alludes to the mental procedure by which people find and take care of countenances in a visual scene.

\section{Face recognition technology}

A facial recognition framework is an innovation equipped for recognizing or checking an individual from a computerized picture or a video outline from a video source. There are numerous strategies wherein facial acknowledgment frameworks work, however all in all, they work by contrasting chosen facial highlights from given picture with faces inside a database. It is likewise depicted as a Biometric Artificial Intelligence based application that can interestingly distinguish an individual by examining designs dependent on the individual's facial surfaces and shape.

\section{RESULT ANALYSIS}

- Face recognition for attendance brought a new trend in recording student's presence which increases the efficiency of students learning by reducing defects that exists in manual model.

The info previously taken is the face example of another understudy. The face design is broken down with the assistance of camera and Arduino assists with controlling the whole procedure. The examples once gathered can be put away in the database alongside the understudies' subtleties. During the section of the understudy, the framework checks for every one of their faces' examples and scans for a comparable match in the database associated. On the off chance that there is a comparative example coordinating for most extreme $85 \%$, at that point a worth 1 is come back to the database which marks participation status for the relating understudy as "present". In any case 0 is returned if there should be an occurrence of miss match and participation is checked "missing". SQL Update Queries can be utilized to accomplish it. Similar qualities are rehashed intermittently and incase on the off chance that any understudy needs to go out, at that point the face design is distinguished by the camera and in the event that the understudies returns inside 15 minutes of holding time, at that point same incentive as the earlier hour is rehashed. In the event that, in the event that the understudy returns late with the information on concerned resources, at that point the worth 1 can be returned as exemption by the personnel later. In the event that none of the two occurs and the understudy returns late, at that point the worth 0 will be returned for consistently until the understudy's faces is recognized and refreshed once more. Thus occasional participation can be accomplished.

\section{CONCLUSION AND FUTURE ENHANCEMENTS}

Face recognition is the optimized method to record pupil attendance. This has the ability to overcome the limitations that exists in the traditional attendance system and RFID. Security and observations are the significant portions which will be profoundly affected. By utilizing robust frameworks of security we can increase the integrity of the system model.

Inclusion of student assessment details such as internal marks, activity marks, contact details etc. makes the system more robust and this makes maintenance of student records easier.

\section{REFERENCES}

1. Author: Wenxian Zeng, Qinglin Meng, Ran Li. "Design of Intelligent Classroom Attendance System Based on Face Recognition", Usage of RFID without any other recognition mechanisms is a great drawback, 2019

2. Author: Md. SajidAkbar, Pronob Sarkar, Ahmad Tamin Mansoor, Abu Musa Al Ashray,Jia Uddin "Face Recognition and RFID Verified Attendance System", The biggest flaw in RFID is that anyone can scan anyone's RFID tag. 2018.

3. Author: Mashhood Sajid, Rubab Hussan, Muhammad Usman. 
"A Conceptual Model for Automated Attendance marking System Using Facial recoganization”, usage of IRIS scanner makes the system more robust rather than using pattern matching, 2014.

4. Author: Shubhobrata Bhattacharya, Gowtham Sandeep Nainala, Prosenjit Das and Aurobinda Routray.

"Smart Attendance Monitoring System(SAMS): A Face Recognition based Attendance System for Classroom Environment", The problem with this system is that it can't recognize the face that is masked, 2018.

5. Author: Soniya V, Swetha Sri R, Swetha Titty K, Ramakrishnan R, Sivakumar $S$

"Attendance Automation Using Face Recognition Biometric Authentication", Training of images consumes more time, which is not negligible, 2017.

6. Author: Lin Zhi-heng, Li Yong-zhen

"Design and Implementation of Classroom Attendance System Based on Video Face Recognition", Video surveillance for attendance is a great approach but still managing such a humongous data is an area of concern, 2019. 